\title{
GRAVITATIONAL RADIATION DETECTOR MAGNETIC TAPES FROM ROCHESTER AND MARYLAND*
}

\author{
M. LEE and J. WEBER
}

University of Maryland, College Park, Md., U.S.A.

\begin{abstract}
The Maryland Univac 1108 computer has analyzed magnetic tapes, one set having outputs of a $1661 \mathrm{~Hz}$ gravitational radiation detector at the University of Maryland and another set having outputs of a $710 \mathrm{~Hz}$ gravitational radiation detector at the University of Rochester. For a seven day period beginning August 23, 1973, 391 coincidences were found. Time delay experiments performed by the computer observed 338 accidental coincides. The zero delay excess is therefore 53 coincidences.

These data have not been verified by the Rochester group and any errors in this report are solely the responsibility of the Maryland authors.
\end{abstract}

* Supported in part by the U.S. National Science Foundation, and the University of Maryland Computer Science Center. 